\title{
THE THIRD TROCHANTER IN HUMAN FEMUR: A CASE REPORT
}

\author{
Rajkumari Ajita ${ }^{1}$, Aribam Jaishree ${ }^{2}$, G. Tempy Sangma ${ }^{3}$, Purnabati S
}

\section{HOW TO CITE THIS ARTICLE:}

Rajkumari Ajita, Aribam Jaishree, G. Tempy Sangma, Purnabati S. "The Third Trochanter in Human Femur: A Case Report". Journal of Evolution of Medical and Dental Sciences 2015; Vol. 4, Issue 41, May 21;

Page: 7224-7228, DOI: $10.14260 /$ jemds/2015/1047

ABSTRACT: During routine osteology demonstration class of 100 numbers of Under Graduate M. B. B. S. Students at the Department of Anatomy, Regional Institute of Medical Sciences, Imphal, Manipur, we have come across one unique and unusual finding that one right human femur was found to be present with an elongated bony projection along the superior border of the gluteal tuberosity. It was found to be present about $7 \mathrm{~cm}$ below the tip of the greater trochanter and the bony projection was about $1.70 \mathrm{~cm}$ in length. It was localised laterally to the line connecting the tip of greater trochanter with superior bifurcation to the linear aspera. No any other anatomical abnormality was found in the above mentioned femur. The other remaining portion of the said femur was found with their normal anatomical features. The photograph of the right human femur mentioned above was taken for proper documentation and for ready reference. This case report has provided some additional evidence to the researchers and anatomists to enhance the understanding of the human femur more particularly the third trochanter and its significance. The present case study revealed an unusual finding as referred to above.

KEYWORDS: Third trochanter, gluteus maximus, human femur, gluteal tuberosity, elongated bony projection.

INTRODUCTION: In human anatomy, the third trochanter is a bony projection occasionally present on the proximal femur near the superior border of the gluteal tuberosity. When present, it is oblong, rounded or conical in shape and sometimes continuous with the gluteal ridge. It generally occurs bilaterally without significant side to side dimorphism. The third trochanter is frequently reported as more common in females than in males. Structures analogous to the third trochanter are present in other mammals, including some primates. It is called the third trochanter in reference to the greater and lesser trochanters that are always present on the femur. Some authors reported that the third trochanter was found frequently present and well developed in Neanderthal femora but not in the femora of many other anthropoid species. ${ }^{[1,2]}$

The third trochanter is defined as the osseous tubercle in the superior part of the gluteal tuberosity. It was present lateral to the line connecting the highest point of the greater trochanter and the superior bifurcation of the linear aspera. ${ }^{[3]}$ In view of paucity of literature on the incidences of third trochanter in Indian population, Ghosh S et al (2014),[3] have conducted a study and their findings were reported.

The third trochanter functions to provide an attachment area for the ascending tendon of the gluteus maximus.[4] This skeleton variant, when present, occurs as an oblong, rounded or conical, roughened or smoothened bony elevation which may be continuous with the gluteal ridge and is manifested as a distinct femoral entity.[1,3] The third trochanter may serve to increase attachment surface area for the gluteal musculature thereby providing greater efficiency of contracture. The majority of the authors describe the role of the third trochanter as the insertion area for the gluteus maximus muscle. 
An additional role of the third trochanter is probably to alternate the direction of the insertion tendon of the gluteus maximus muscle. The most interesting issue concerning the third trochanter in humans is whether it is a structure homologous to the third trochanter of other mammals and if so, why it is absent in many primates, including apes, yet still frequent in humans.[1,2]

Expression of the third trochanter may be affected by mechanical stress exerted by the gluteus maximus; this muscle functions to decrease limb speed during the late swing and heel strike phases of locomotion. The third trochanter may perhaps serve to increase attachment surface area for the gluteal musculature thereby providing greater efficiency of contraction. Gluteus maximus function may exert a mechanical loading on the third trochanter thereby altering surface morphology.

The presence of bony crests, ridges and tuberosities are directly correlated to the function of contiguous muscle activity.[1,3] The phenotypic development and expression of discontinuous skeletal traits (including the rarely occurred third trochanter) were originally considered to be controlled by genetic factors. ${ }^{[5]}$ Recent researches indicate the significance of various biological and environmental factors such as age, sex, nutritional status or side dependence influencing the manifestation of certain non-metric traits in non-human and human populations. $[6,7,8]$ Local mechanical factors also represent potent sources of epigenetic information which influence the incidence and expression of discontinuous variant. $[1,9,10]$

CASE REPORT: During routine osteology demonstration class of 100 numbers of Under Graduate M. B. B. S. Students at the Department of Anatomy, Regional Institute of Medical Sciences, Imphal, Manipur, we have come across one unique and unusual finding that one right human femur was found to be present with an elongated bony projection along the superior border of the gluteal tuberosity. It was found to be present about $7 \mathrm{~cm}$ below the tip of the greater trochanter (Figure - 1) and on careful measurement with a measuring tape, the bony projection was found to be about 1.70 $\mathrm{cm}$ in length (Figure - 2). It was localised laterally to the line connecting the tip of greater trochanter with superior bifurcation to the linear aspera. No any other anatomical abnormality was found in the above mentioned femur. The other remaining portion of the said femur was found with their normal anatomical features. The photograph of the right femur mentioned above was taken for proper documentation and for ready reference.

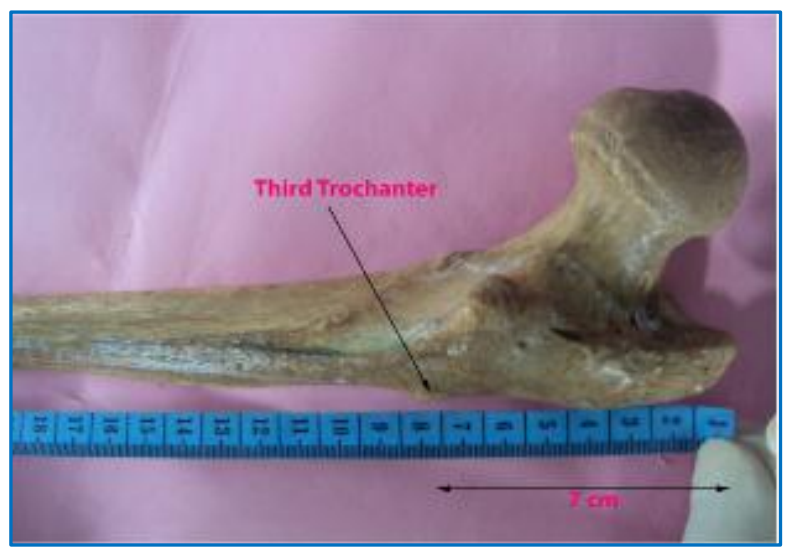

Fig. 1: Photograph showing the location of the third trochanter in the right human femur under report 


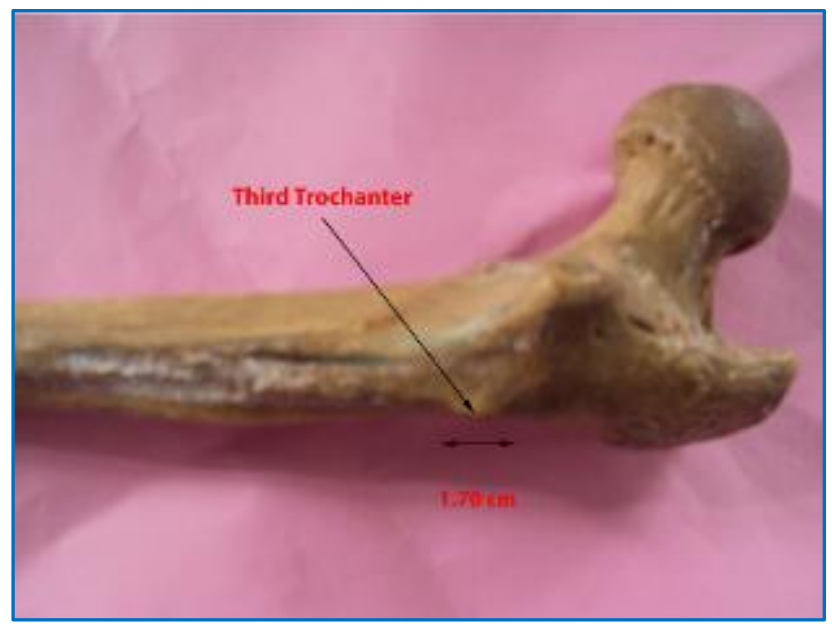

Fig. 2: Photograph showing the approximate length of the third trochanter in the right human femur under report

DISCUSSION: Bolanowski W et al (2005),[2] in one study tried to analyse the occurrence of the third trochanter and its correlation with the morphology of the human femur. The third trochanter was found in 38 of 622 (6.2\%) human femora taken from 3 excavation sites. 36 of these were included in their study and were compared to the femora without the third trochanter. The bones with the third trochanter were characterised by a greater superior sagittal diameter and diaphysis platymetry index as well as a larger greater trochanter. These results suggest that the third trochanter is not a progressive morphological feature of the skeleton. Rather, it is connected with an altered gluteal muscle function.[2] The study conducted by Lozanoff $S$ et al (1985),[1] indicated that the third trochanter incidence is associated with short femora displaying robust proximal diaphyses. The gluteus maximus muscle may act as a primary factor governing third trochanter expression. Further, this infracranial discrete trait appears well suited for human taxonomy studies. However, in our present study, the length of aforesaid human right femur, where the third trochanter was observed, is found moderately long.

Ghosh S et al (2014),[3] stated that the incidence of the third trochanter in their study was found to be about $6.6 \%$ with left sided predominance. Whereas, in our present study, we have observed one unique and unusual finding that only one right human femur (Out of 100 human femora), that is only $1 \%$ was found to be present with an elongated bony projection along the superior border of the gluteal tuberosity, which is considered quite unique and unusual, thereby showing a significantly high degree of difference between the study conducted by Ghosh $\mathrm{S}$ et al and the present study. As such, this unique and unusual finding deserves to be reported as a special case report. The incidence of the third trochanter in one study is $6.6 \%$ with left sided predominance; it also displays a gender variation, being higher in males. Their results are comparable to a study done on excavated femora from Poland which showed an incidence of $6.2 \%$. However, they did not take any gender or side variations into consideration. ${ }^{[2]}$

Another study which reported the side variations in Whites and Negroes, documented higher incidence on the right side in the White and on the left side in the Negro population; it also reported the trait to be more common in females in both Whites and Negroes. The study reported that the incidence of the third trochanter in the human femur is about 6.1\%.[11] The present study showed the 


\section{CASE REPORT}

third trochanter incidence only on the right side human femur with $1 \%$ occurrence, the sex of which was also not known. However, one of the limitations of the present study is the absence of any record that could help us in the determination of the sex of bones.

CONCLUSION: Ghosh S et al (2014),[3] reported that the presence of third trochanter at the proximal part of the femur has been found to alter the break lines in the pertrochanteric fracture patients. Their study dealt with the incidence of third trochanter in the Indian population due to scant previous literatures. The knowledge of the occurrence would be crucial for the diagnosis and management of pertrochanteric fractures and also in the study of microevolutionary trends in the anthropometric and comparative studies of humans. Whereas, Bolanowski W et al (2005),[2] in their study reported that the third trochanter is not a progressive morphological feature of the skeleton. Rather, they reported that the third trochanter is a structure which is correlated with an altered gluteal muscle function. The third trochanter is associated with short robust femora as determined in a study conducted by Lozanoff $S$ et al (1985),[1] and represents an important feature for describing a general morphological pattern of the human diaphysis in a given population. Hence, the third trochanter should prove useful when included in batteries of nonmetric traits for discrimination among human population.

This present case report has provided some additional evidence to the researchers and anatomists to enhance the understanding of the human femur more particularly the third trochanter and its significance. Our case report revealed a unique and unusual finding that one right human femur was found to be present with an elongated bony projection along the superior border of the gluteal tuberosity. Since sufficient numbers of literatures in this regard are not found readily, it is recommended that more and more thorough and detailed research works should be done by various workers and such workers be encouraged to explore such unique and unusual findings.

\section{REFERENCES:}

1. Lozanoff S, Sciulli PW, Schneider KN. Third trochanter incidence and metric trait covariation in the human femur. J Anat. 1985 Dec; 143: 149-59.

2. Bolanowski W, Smiszkiewicz-Skwarska A, Polguj M, Jedrzejewski KS. The occurrence of the third trochanter and its correlation to certain anthropometric parameters of the human femur. Folia Morphol. 2005; 64 (3): 168-75.

3. Ghosh S, Sethi M, Vasudeva N. Incidence of third trochanter and hypotrochanteric fossa in human femora in Indian population. OA Case Reports 2014 Feb 25; 3 (2): 14.

4. Soames RW. Skeletal System. Gray's Anatomy. 38 th Edition. Edinburgh: Churchill Livingstone; 1995. p. 682.

5. Carolineberry A, Berry RJ. Epigenetic variation in the human cranium. J Anat. 1967 Apr; 101 (Pt 2): 361-79.

6. Howe WL and Parsons PA. Genotype and environment in the determination of minor skeletal variants and body weight in mice. J Embryol Exp Morphol 1967; 17: 283-92.

7. Dahinten SL, Pucciarelli HM. Effect of age, sex and nutrition on discontinuous traits of rat skull. Acta Anat (Basel). 1981; 110 (2): 159-63.

8. Pucciarelli HM. The influence of experimental deformation on neurocranial Wormian bones in rats. Am. J. Phys. Anthropol. 1974; 41: 29-37.

9. Moss ML. Genetics, epigenetics and causation. Am J Orthod. 1981 Oct; 80 (4): 366-75. 


\section{CASE REPORT}

10. Moss ML, Moss-Salentijin L. The muscle bone interface: An analysis of a morphological boundary. 1978. p39-71. Monograph 8, Ann Arbor, Centre for Human Growth and Development, University of Michigan.

11. Finnegan M. Non-metric variation of the infracranial skeleton. J Anat. 1978 Jan; 125 (Pt 1):2337.

\section{AUTHORS: \\ 1. Rajkumari Ajita \\ 2. Aribam Jaishree \\ 3. G. Tempy Sangma \\ 4. Purnabati $S$}

\section{PARTICULARS OF CONTRIBUTORS:}

1. Associate Professor, Department of Anatomy, Regional Institute of Medical Sciences, Imphal, Manipur, India.

2. Associate Professor, Department of Anatomy, Regional Institute of Medical Sciences, Imphal, Manipur, India.

3. Assistant Professor, Department of Anatomy, Regional Institute of Medical Sciences, Imphal, Manipur, India.

FINANCIAL OR OTHER COMPETING INTERESTS: None
4. Assistant Professor, Department of Anatomy, Regional Institute of Medical Sciences, Imphal, Manipur, India.

\section{NAME ADDRESS EMAIL ID OF THE CORRESPONDING AUTHOR:}

Dr. Rajkumari Ajita,

Pishumthong Oinam Leikai, Imphal, West District,

P. O. Imphal-795001, Manipur.

E-mail: rajkumariajita13@yahoo.com

Date of Submission: 26/04/2015. Date of Peer Review: 27/04/2015. Date of Acceptance: 13/05/2015. Date of Publishing: 21/05/2015. 